\title{
Competência Percebida e Atribuição de Causalidade em Jogadores Juniores de Futebol
}

\author{
Lucas Guimarães Cardoso de Sá1 \\ Marilia Ferreira Dela Coleta \\ José Augusto Dela Coleta \\ Universidade Federal de Uberlândia
}

\begin{abstract}
RESUMO - O modelo motivacional da atribuição de causalidade prevê que sentimentos e expectativas gerados pelo tipo de causa utilizada pelo indivíduo, para explicar o que acontece com ele mesmo, podem influenciar sua motivação. Assim, pretendeu-se investigar as causas atribuídas por 111 jogadores juniores de futebol ao próprio nível de competência e sua influência nos sentimentos, expectativas e disposição para agir. Os resultados indicaram que aqueles que avaliaram ter alto nível de competência utilizaram causas mais internas, mais estáveis e igualmente controláveis, em comparação àqueles que avaliaram ter um nível menor de competência. Isso pode explicar a ausência de diferenças significativas nas emoções negativas, expectativas e disposições para a ação dos atletas.
\end{abstract}

Palavras-chave: causalidade; competência; motivação; futebol.

\section{Perceived Competence and Causal Attribution of Junior Football Players}

\begin{abstract}
The motivational model of causal attribution predicts that emotions and expectations generated by the type of cause utilized by a person, to explain what happens to himself, can influence his motivation. Therefore, the present study aimed to investigate the causes attributed by 111 junior football players to their competence level and its influence on their emotions, expectations and disposition for the action. The results showed that those who evaluated having a high competence level utilized more internal, more stable and equally controllable causes comparing to those who evaluated having a lower competence level. This may explain the absence of significant differences in negative emotions, expectations, and dispositions for the action of athletes.
\end{abstract}

Keywords: causality; competence; motivation; football.

No mundo da preparação física e dos esportes, tem sido comum a utilização do termo no pain no gain, que numa tradução livre significa algo como "sem dor não há resultado". Nada parece representar melhor a função motivacional dos processos de atribuição de causalidade ou, como a causa atribuída a um resultado pode influenciar o comportamento de um atleta. $\mathrm{O}$ conceito nada mais é que um incentivo para o máximo esforço, para que o esportista acredite que este esforço é a causa responsável por seu nível de competência e pelo consequente sucesso no esporte, sendo também uma forma de mantê-lo motivado, mesmo diante das dificuldades.

$\mathrm{O}$ behaviorismo, ao demonstrar que todo indivíduo está sujeito ao controle de forças externas a ele, mudou a concepção do homem como ser totalmente livre para fazer suas escolhas. A partir disso pode-se dizer que um indivíduo não age a seu bel-prazer e sim a partir de inúmeros outros estímulos, sendo muitos fora de seu controle pessoal. $\mathrm{Na}$ verdade, os estímulos em si são menos importantes se comparados à percepção que se tem deles, esta sim considerada determinante para o comportamento. Por exemplo, para um jogador de futebol que precisa atuar bem em um jogo decisivo, importa mais a percepção que ele tem do nível de

1 Endereço para correspondência: Lucas Guimarães Cardoso de Sá. Universidade Federal de Uberlândia. Avenida Maranhão, s/no , Bloco 2C, Sala 2C54 - Campus Umuarama. Jardim Umuarama, Uberlândia, MG, CEP: 38400902 - Caixa Postal: 593.E-mail: lucas.gcs@gmail.com cobrança da torcida que a real cobrança que ela faz ao atleta. Se ele percebe uma cobrança exagerada, esta provavelmente será a causa utilizada pelo atleta para justificar um possível desempenho ruim, pouco adiantando que na realidade ela seja menor.

O psicólogo austríaco Fritz Heider (1958) foi um dos primeiros a escrever sobre como as pessoas buscam explicações para os eventos ocorridos. Baseado nos estudos sobre percepção social e relações interpessoais, Heider postulou que o homem não fica satisfeito em apenas observar os eventos que o cercam, ele tem necessidade de estabelecer uma relação de causa e efeito entre eles. $\mathrm{O}$ resultado seria um mundo mais predizível, controlável e seguro, uma vez que essa relação permitiria saber o que esperar de situações semelhantes no futuro. Sabendo-se ainda que as ações individuais são determinadas pela maneira como as cognições sobre o mundo e as outras pessoas estão estruturadas, é possível afirmar que os processos de atribuição causal exercem um papel fundamental no comportamento humano.

Na década de 1970, Bernard Weiner, baseando-se nas ideias de Fritz Heider, propôs um modelo de atribuição capaz de explicar a motivação do indivíduo por meio das causas utilizadas por ele para justificar seu sucesso ou insucesso em determinadas tarefas e situações específicas. Weiner et al. (1972) afirmaram que devido às inúmeras causas imagináveis para explicar o sucesso ou insucesso em uma tarefa, 
seria fundamental criar um esquema de classificação ou taxionomia para elas.

E foi o que esses autores fizeram depois de verificar que as causas atribuídas a situações de sucesso ou insucesso poderiam ser classificadas em poucas propriedades ou dimensões bipolares. A primeira foi denominada locus da causalidade e diz respeito ao local onde a pessoa acredita estar a causa para um evento particular, se dentro dela mesma ou em outras pessoas, entidades, ambiente, etc. A segunda, designada de grau de estabilidade da causa, engloba as causas estáveis ou instáveis, dependendo de serem ou não duradouras, de assumirem ou não as mesmas topologias ao longo do tempo.

Durante um período este modelo com duas dimensões foi dominante, mas com a sequência de estudos, acabou sofrendo importantes alterações. A principal delas foi a inclusão de uma terceira dimensão atribuicional chamada por Weiner (1979) de controlabilidade da causa, contendo os pólos controlável e incontrolável e referindo-se ao quanto o indivíduo que vivencia a situação percebe que pode, por vontade própria, alterar ou não aquela causa em particular.

Weiner (1979), destacando a subjetividade na classificação das causas, fez a ressalva de que muitas vezes indivíduos diferentes podem perceber uma mesma causa como pertencendo a dimensões diferentes. Por exemplo, a falta de capacidade ou de habilidade, causa aparentemente estável, pode ser percebida como instável se a pessoa acreditar na possibilidade do aprendizado. Também se pode ter a percepção de que a causa "dificuldade da tarefa" é instável se houver a crença de que ela pode mudar e se tornar mais fácil ou mais difícil. De forma semelhante, é possível que o indivíduo entenda o esforço como um traço constante do indivíduo ou a sorte como uma característica pessoal (i.e. pessoa sortuda ou azarada), o que conferiria características estáveis a estas explicações (Weiner, 1985).

De acordo com a teoria intrapessoal da motivação de Weiner (2000), o processo motivacional tem início quando, após um evento ou situação, o indivíduo busca uma causa para explicar as razões pelas quais o resultado ocorreu. Há uma tentativa de responder a perguntas como "Por que isso aconteceu? Qual foi a causa desse resultado?" Essa busca, porém, não é feita em todas as situações, sendo mais provável que ocorra naquelas em que o resultado foi negativo, inesperado e importante.

Ao responder 'por que' aquele resultado ocorreu, uma ou mais causas são então selecionadas. De acordo com Weiner (1985, 2000), a não ser em casos muito especiais, todas as razões fornecidas pelos indivíduos para a ocorrência de situações de sucesso ou insucesso poderiam ser classificadas em apenas oito causas: capacidade, esforço sistemático, esforço não sistemático, estado de ânimo, ajuda sistemática, ajuda não sistemática, características da atividade e acaso. Estas causas seriam resultantes da combinação dos dois pólos de cada uma das três dimensões já referidas. No entanto, de acordo com o mesmo autor, mais que a causa em si, são as dimensões presentes nestas causas as responsáveis pelos aspectos motivacionais. Por isso, para que a consequência motivacional das causas atribuídas seja entendida, é preciso que seja analisado o quanto há de estabilidade, controlabilidade e internalidade/ externalidade em cada explicação (Weiner, 2000). Nesse processo, as dimensões causais acabam gerando consequências importantes em dois aspectos psicológicos da motivação do indivíduo: expectativas e emoções (Weiner, 1985, 2000). A união destes dois componentes, já devidamente influenciados pelas dimensões causais, pode determinar que tipo de comportamento o indivíduo emitirá.

O processo de atribuição de causas é iniciado a cada situação distinta na qual uma explicação é buscada pelo indivíduo. Contudo, pode haver uma tendência, chamada de estilo atribuicional, de utilizar as mesmas causas explicativas (consequentemente as mesmas combinações dimensionais) de forma recorrente. Enquanto alguns teriam um estilo atribuicional otimista, utilizando causas internas, estáveis e controláveis para o sucesso e causas externas, instáveis e controláveis para o insucesso, outros teriam um estilo pessimista, com atribuiçõoss inversas para o sucesso e o insucesso. Aqueles que utilizam mais frequentemente o estilo otimista apresentariam melhor desempenho em diversas tarefas, inclusive nas esportivas (Rodrigues, 2007).

No estilo otimista, em situações de insucesso, o controle pessoal precisa ser percebido como elevado, uma vez que sua ausência pode levar a um fenômeno chamado desamparo aprendido, que se caracteriza quando a pessoa percebe não ser capaz de exercer qualquer controle sobre a situacao adversa, ficando totalmente passiva e desistindo de qualquer tentativa de escape. Para Le Foll, Rascle e Higgins (2006, 2008) atribuições otimistas são funcionais, uma vez que ajudam a manter a persistência do indivíduo na tarefa, enquanto atribuições pessimistas têm efeito justamente contrário.

No esporte, Rees, Ingledew e Hardy (2005) apontaram que os estudos sobre o processo atribuicional tiveram início ainda na década de 1970, alcançando seu auge nos anos 1980. No início da década de 1990 houve uma diminuição na quantidade de estudos e, a partir do seu final, um novo crescimento, que parece seguir até os dias atuais. No início, as pesquisas buscavam métodos seguros de mensuração das dimensões causais, passando com o tempo a verificar a relação entre dimensões causais e emoções e expectativas dos atletas. Atualmente, os pesquisadores da área parecem interessados em testar o modelo, principalmente diante de situações de insucesso, observando como diferentes tipos de atribuição geram maior ou menor motivação e persistência em uma tarefa esportiva.

Em língua portuguesa, sobressaem-se algumas pesquisas realizadas em Portugal, uma vez que são raras as publicações brasileiras sobre o assunto. Assim, devido à necessidade de se compreender os aspectos psicológicos de esportistas brasileiros, considerando as diferenças culturais existentes e sabendo-se que o futebol é o esporte mais popular do país, foi desenvolvido este estudo, com o objetivo de testar, no esporte, alguns dos pressupostos contidos na teoria intrapessoal da motivação de Bernard Weiner e já verificados em contexto educacional e empresarial. Para isso, foram investigadas as causas atribuídas por jogadores de futebol da categoria júnior (na qual é permitida a atuação de jogadores com até 20 anos de idade) ao seu nível de competência percebido e as relações entre essas causas e os sentimentos, expectativas e disposição futura para agir dos jovens atletas. 


\section{Método}

\section{Participantes}

A amostra foi composta por 111 jogadores de futebol da categoria júnior, todos do sexo masculino, com até 20 anos de idade $(M=18,23)$. Apenas $8,1 \%$ deste total cursavam o ensino superior, enquanto a maioria $(47,7 \%)$ afirmou ter concluído apenas o ensino médio e $44,1 \%$ sequer o tenha feito. Dos 111 atletas, 39,64\% são defensores, 36,04\% são meio-campistas e $24,32 \%$ atacantes.

\section{Instrumentos}

Foi utilizada uma entrevista estruturada contendo 39 perguntas envolvendo as variáveis do processo atribuicional proposto por Weiner $(1985,2000)$. Com exceção da causa atribuída ao nível de competência percebida, em forma de resposta aberta, todas as demais deveriam ser respondidas em uma escala numérica entre 1 e 10 , sendo 1 o menor e 10 o maior nível possível de resposta.

Com base no método utilizado por Rudisill (1989), o nível de competência percebido foi medido por meio da pergunta "Que nota você dá para você mesmo como jogador de futebol?", à qual o sujeito indicava sua resposta em uma escala entre 1 e 10 . Em seguida, para identificar a causa utilizada para explicar este nível de competência percebido, era feita a pergunta "Qual a principal causa, o principal motivo que explica essa nota que você deu para você na questão anterior? (porque você tem essa nota como jogador de futebol)?".

Como Weiner (1985) afirmou que as dimensões são mais importantes que a causa em si, foram elaboradas três questões às quais os sujeitos deveriam indicar o quanto aquela causa era identificada por ele como interna ("o quanto esta causa está relacionada a você?"), estável (“o quanto você acredita que esta causa vai continuar se repetindo no futuro?") e controlável ("o quanto você acredita poder controlar pessoalmente esta causa?").

Para verificar as relações entre dimensões causais e sentimentos dos atletas, foram propostas 25 questões contendo as emoções mais comumente utilizadas para explicar a causalidade de um evento, identificadas nos estudos de Weiner, Russell e Lerman (1978) e confirmadas no meio brasileiro por Dela Coleta e Godoy (1986). Segundo os autores, diante de uma situação em que há percepção de sucesso o indivíduo tende a se sentir competente, confiante, vitorioso, recompensado, realizado, orgulhoso, aliviado, capaz, tranquilo, seguro, agradecido, relaxado, motivado ou surpreso. Diante de uma situação de insucesso, tende a se sentir conformado, arrependido, frustrado, desanimado, deprimido, angustiado, revoltado, com raiva, cansado, envergonhado, culpado ou também surpreso.

As perguntas utilizadas para explorar estas relações foram "sabendo que você é um jogador nota X pelo motivo Y, o quanto você se sente... (sentimento)... como jogador de futebol?", sendo uma pergunta para cada um dos 25 sentimentos. Tais procedimentos estão baseados naqueles utilizados por McAuley, Russell e Gross (1983) para a mesma finalidade.
As expectativas foram investigadas por meio de cinco questões envolvendo profissionalismo ("o quanto você acredita que um dia poderá ser jogador profissional de futebol?"), sucesso no profissionalismo ("o quanto você acredita que um dia poderá ser um jogador profissional de futebol e ter sucesso nessa carreira?") e nível de competência a curto, médio e longo prazo ("se você fosse responder daqui a um mês/um ano/cinco anos, que nota você acredita que se daria como jogador de futebol?").

Por fim, as disposições para a ação foram analisadas por meio de outras quatro questões relativas ao quanto o indivíduo estaria disposto a mudar ou executar novos comportamentos visando ser um jogador de futebol com maior nível de competência. As perguntas foram: "de 1 a 10, quantas vezes mais você está disposto a se esforçar para ser um grande jogador de futebol?"; "se fosse preciso aumentar o tempo de treinamento para você se tornar um grande jogador de futebol, o quanto (de 1 a 10) você estaria disposto a aumentar?"; "de 1 a 10, o quanto você abriria mão das horas de diversão (de festas, de lazer, de convívio em família) para se tornar um grande jogador de futebol?" e "de 1 a 10, o quanto você aceitaria que o treinador fosse mais exigente com você, para você se tornar um grande jogador de futebol?".

\section{Procedimentos}

A maioria das entrevistas foi realizada antes dos jogos, quando os atletas chegavam para as partidas ou logo após seu final, enquanto se preparavam para partir. O pesquisador fazia as perguntas e anotava as respostas em folhas individuais, levando entre cinco e dez minutos para preencher todo o instrumento. As respostas foram transformadas em códigos numéricos, digitadas em uma planilha da versão 15 do programa de computador SPSS e analisadas estatisticamente, por meio de médias, desvios padrão, testes de diferença entre médias e regressão múltipla. Para esta análise estatística, as respostas referentes aos sentimentos positivos (aqueles relacionados ao sucesso em estudos anteriores), aos sentimentos negativos (relativos ao insucesso), às expectativas e às disposições para a ação foram aglutinadas através da soma dos valores fornecidos para suas múltiplas questões e formaram quatro escores, um para cada uma destas variáveis.

Para a interpretação da única questão aberta do estudo - aquela em que o jogador deveria explicar o nível de competência percebido - foi feita uma análise qualitativa dos dados. Nela, contou-se com a colaboração de juízes, pesquisadores doutores e conhecedores da teoria do processo de atribuição de causalidade, que seguiram as orientações de Bardin (1970) sobre a formação de categorias e decidiram em consenso quais conteúdos das respostas pareciam explicar o maior nível de competência percebido e quais pareciam justificar a percepção de um nível menor. Assim, a partir dessa avaliação, as respostas foram separadas em duas categorias distintas: maior e menor percepção de competência. Em seguida, foram novamente divididas, agora dentro de cada categoria formada anteriormente, de acordo com as oito possíveis causas propostas por Weiner $(1985,2000)$ como resultantes do processo atribuicional: capacidade, esforço sistemático, 
esforço não sistemático, estado de ânimo, ajuda sistemática, ajuda não sistemática, características da atividade ou acaso.

\section{Resultados}

A média do grupo com maior competência percebida foi de $8,51(D P=1,47)$, e do grupo de menor competência percebida foi de 7,23 $(D P=1,12)$, sendo essa diferença significativa $(t=5,17, p<0,001)$. Atletas com maior nível de competência percebido atribuíram esse fato a duas causas: capacidade $(n=20$; respostas como "porque jogo muito" ou "porque sou ágil e chuto bem") ou esforço sistemático ( $n=31$; respostas como "porque sou esforçado" ou "porque me dedico"). Por outro lado, aqueles com menor nível de competência percebido utilizaram três tipos de causa: a falta de capacidade $(n=35$; respostas do tipo "porque não sou [um jogador] muito bom mesmo" ou "porque não sou bom marcador"), a falta de esforço sistemático ( $n=17$; respostas como "porque não me dedico o suficiente nos treinos") ou características da atividade ( $n=8$, respostas como "porque o clube não me oferece condições de ser um bom jogador").

Contudo, como Weiner (1985) afirmou, as causas atribuídas importam menos que suas dimensões. Os resultados para esta amostra, como mostrados na Tabela 1, indicaram que atletas com maior nível de competência percebido fizeram atribuições em média mais internas e mais estáveis quando comparados àqueles com menor percepção de nível de competência. Para a controlabilidade pessoal não houve diferença significativa entre os grupos, o que significa que atletas com menor percepção de competência não fizeram atribuições menos controláveis em relação àqueles com maior competência percebida. Cabe ressaltar que apesar de não ter sido significativo, o valor de $p=0,06$ ficou próximo a 0,05 , valor convencionalmente adotado como tal. Assim, comparativamente, é possível afirmar que ao maior nível de competência percebido são atribuídas causas internas, estáveis e controláveis, enquanto ao menor nível percebido são utilizadas causas externas, instáveis e controláveis.

Por meio dos resultados das análises de regressão simples efetuadas, encontrou-se que o nível de competência percebido é preditor das três dimensões atribuicionais, explicando $4 \%$ da variância do locus da causalidade $\left(\mathrm{R}^{2}=0,04 ; \mathrm{F}(1,109)=4,03\right.$ $; p<0,05 ; \beta=0,19), 9 \%$ do grau de estabilidade $\left(\mathrm{R}^{2}=0,09\right.$ ; F $(1,109)=10,66 ; p<0,01 ; \beta=0,30)$ e $11 \%$ do controle pessoal $\left(\mathrm{R}^{2}=0,11 ; \mathrm{F}(1,109)=13,09 ; p<0,001 ; \beta=0,33\right)$.

Como pode ser observado na Tabela 2 , a mensuração das reações emocionais dos atletas mostrou que, independentemente da percepção de maior ou de menor nível de competência, sentimentos positivos apresentaram maiores médias que aqueles com conotação negativa. Apesar disso, e mais importante, é ressaltar que aqueles com menor percepção de competência parecem experimentar significativamente menos sentimentos positivos quando comparados àqueles que se percebem como tendo maior nível. Por outro lado, não foi encontrada diferença significativa entre os grupos em relação aos sentimentos negativos.

Em relação às expectativas, como apresentado na Tabela 3 , jogadores que fizeram atribuições internas, estáveis e controláveis à maior competência percebida apresentaram, de forma geral, média mais elevada que aqueles que fizeram atribuições externas, instáveis e controláveis à menor percepção de competência. Contudo, a diferença não foi significativa, o que sugere que as expectativas dos futebolistas dessa amostra não diferem quando se considera os diferentes níveis de competência encontrados.

Também na Tabela 3 , em relação às disposições para a ação, atletas que fizeram atribuições internas, estáveis e controláveis à maior competência percebida tiveram, de forma geral e em termos absolutos, médias mais elevadas que aqueles que fizeram atribuições externas, instáveis e controláveis para a menor competência percebida. No entanto, o teste $\mathrm{t}$ de Student indicou que novamente a diferença não atingiu níveis de significância estatística.

A partir desses dados, foram realizadas análises de regressão para identificar a influência das três dimensões causais nos dois grupos de sentimentos e nas expectativas dos atletas. Seguindo a afirmação de Weiner (2000), de que as disposições para a ação são resultado da influência das emoções e expectativas, foram também realizadas análises de regressão nesse sentido para testar tal hipótese.

Os resultados apresentados na Tabela 4 indicam que as três dimensões atribuicionais explicam $9 \%$ da variância em relação às emoções positivas e $10 \%$ da variância nas expectativas dos jogadores, não sendo significativa a explicação para emoções negativas. Cabe ressaltar que em ambos os casos, a controlabilidade foi a única dimensão significativamente influente. No primeiro caso, o valor de $\beta=0,26(t=2,41$, $\mathrm{p}=0,02$ ) permite dizer que quando a controlabilidade aumenta um desvio padrão, os sentimentos positivos aumentam a 0,26 desvio padrão. No segundo, $\operatorname{com} \beta=0,21(\mathrm{t}=1,96 ; \mathrm{p}=0,05)$, para cada desvio padrão aumentado em relação ao controle pessoal há um aumento a 0,21 desvio padrão nas expectativas dos atletas.

Como mostra a Tabela 5, a interação entre emoções positivas, negativas e expectativas explica $35 \%$ da variância em relação às disposições para a ação. É importante destacar que as expectativas e os sentimentos negativos se mostraram mais relacionados com as disposições para a ação. Para cada desvio padrão aumentado em relação aos sentimentos negativos as disposições para a ação aumentam a 0,24 desvio padrão ( $\beta=0,24, t=3,12, p<0,01)$ e para cada desvio padrão aumentado em relação às expectativas as disposições para a ação aumentam a 0,55 desvio padrão $(\beta=0,55, \mathrm{t}=6,89, \mathrm{p}<0,001)$.

\section{Discussão}

Este estudo foi desenvolvido sob a perspectiva de que as causas que jogadores de futebol acreditam ser responsáveis por seu maior ou menor nível de competência percebida no futebol (o que de certa forma equivale à sua percepção de sucesso ou insucesso no esporte) talvez possam ajudar a elaborar uma preparação psicológica mais adequada e específica aos atletas. Um exemplo disso seria a possibilidade de descobrir quais são as atribuições mais funcionais aos atletas, aquelas que proporcionam mais sentimentos positivos, menos sentimentos negativos e maiores expectativas e disposições para a ação, incentivando-as incessantemente. 
Tabela 1. Média, Desvio Padrão e Análise da Diferença de Médias Entre as Dimensões da Causa de Acordo Com o Maior ou Menor Nível de Competência Percebido Por Jogadores Juniores de Futebol

\begin{tabular}{|c|c|c|c|c|c|c|}
\hline \multirow[t]{2}{*}{ Dimensão da Causa } & \multicolumn{2}{|c|}{$\begin{array}{l}\text { Maior percepção } \\
\text { de competência }\end{array}$} & \multicolumn{2}{|c|}{$\begin{array}{c}\text { Menor percepção } \\
\text { de competência }\end{array}$} & \multirow[b]{2}{*}{$t$} & \multirow[b]{2}{*}{$(p)$} \\
\hline & $M$ & $(D P)$ & $M$ & $(D P)$ & & \\
\hline Locus da causalidade & 8,35 & $(1,35)$ & 7,43 & $(1,92)$ & 2,94 & $(0,004)$ \\
\hline Grau de estabilidade & 8,12 & $(2,07)$ & 5,83 & $(2,80)$ & 4,95 & $(0,001)$ \\
\hline Controle pessoal & 7,94 & $(1,51)$ & 7,25 & $(2,19)$ & 1,90 & (n.s.) \\
\hline
\end{tabular}

Nota: n.s.= não significativo

Tabela 2. Média, Desvio Padrão e Análise da Diferença de Médias Entre Sentimentos Com Conotação Positiva e Negativa de Jogadores Juniores de Futebol de Acordo Com o Nível de Competência Percebido

\begin{tabular}{lccccccc}
\hline \multirow{2}{*}{ Sentimentos } & \multicolumn{2}{c}{$\begin{array}{c}\text { Maior percepção de } \\
\text { competência }\end{array}$} & \multicolumn{2}{c}{$\begin{array}{c}\text { Menor percepção de } \\
\text { competência }\end{array}$} \\
\cline { 2 - 8 } & $\boldsymbol{M}$ & $(\boldsymbol{D P})$ & $\boldsymbol{M}$ & $(\boldsymbol{D P})$ & $\boldsymbol{t}$ & $(\boldsymbol{p})$ \\
\hline Positivos & 8,13 & $(0,98)$ & 7,62 & $(1,11)$ & $(1,57)$ & 0,15 & $(0,01)$ \\
\hline Negativos & 4,30 & $(1,63)$ & 4,26 & $($.s.s.) \\
\hline
\end{tabular}

Nota: n.s.= não significativo

Tabela 3. Média, Desvio Padrão e Análise da Diferença de Médias Entre Expectativas e Disposições Para a Ação de Jogadores Juniores de Futebol, de Acordo Com o Nível de Competência Percebido

\begin{tabular}{|c|c|c|c|c|c|c|}
\hline \multirow[t]{2}{*}{ Variáveis } & \multicolumn{2}{|c|}{$\begin{array}{l}\text { Maior percepção de } \\
\text { competência }\end{array}$} & \multicolumn{2}{|c|}{$\begin{array}{l}\text { Menor percepção de } \\
\text { competência }\end{array}$} & \multirow[b]{2}{*}{$t$} & \multirow[b]{2}{*}{$(p)$} \\
\hline & $M$ & $(D P)$ & $M$ & $(D P)$ & & \\
\hline Expectativas & 8,23 & $(1,61)$ & 7,77 & $(1,11)$ & 1,47 & (n.s.) \\
\hline Disposições para a ação & 9,24 & $(1,35)$ & 9,07 & $(1,57)$ & 0,69 & (n.s.) \\
\hline
\end{tabular}

Nota: n.s.= não significativo

Tabela 4. Resumo Das Análises de Regressão Múltipla Para Dimensões Atribuicionais Prevendo Emoções e Expectativas em Jogadores Juniores de Futebol

\begin{tabular}{llllll}
\hline Preditores & Variável Critério & $\mathbf{R}$ & $\mathbf{R}^{\mathbf{2}}$ & $\mathbf{F}$ & $\boldsymbol{p}$ \\
\hline & Emoções positivas & 0,30 & 0,09 & 3,41 & 0,02 \\
$\begin{array}{l}\text { Locus da causalidade, grau de estabili- } \\
\text { dade e controlabilidade }\end{array}$ & Emoções negativas & 0,09 & 0,01 & 0,31 & n.s. \\
& Expectativas & 0,32 & 0,10 & 3,96 & 0,01 \\
\hline
\end{tabular}

Nota: n.s.= não significativo

Tabela 5. Resumo Das Análises de Regressão Múltipla Para Emoções e Expectativas Prevendo Disposições Para a Ação em Jogadores Juniores de Futebol

\begin{tabular}{llllll}
\hline Preditores & Variável Critério & $\mathbf{R}$ & $\mathbf{R}^{\mathbf{2}}$ & $\mathbf{F}$ & $\boldsymbol{p}$ \\
\hline Emoções positivas & Disposições para a ação & 0,60 & 0,35 & 19,15 & 0,001 \\
$\begin{array}{l}\text { Emoções negativas } \\
\text { Expectativas }\end{array}$ & & & & & \\
\hline
\end{tabular}


As causas usadas pelos participantes para explicar a maior competência percebida incluíram a habilidade (presença de características positivas gerais ou específicas) e o esforço (dispendido durante treinos, jogos ou no dia-a-dia, na vida pessoal), ou seja, se consideram bons jogadores de futebol porque têm alguma capacidade ou porque se empenham. Já a menor competência percebida foi justificada por meio de três fatores: falta de capacidade (ausência geral ou específica de características positivas), falta de esforço sistemático e características da tarefa que interferem e impedem que os jogadores alcancem um maior nível de competência.

As respostas relativas à falta de capacidade pareceram estar relacionadas a pouca idade dos atletas, que por serem muito novos ainda não estão formados, tendo muito a aprender. A crença parece ter sido de que as habilidades que faltam virão naturalmente, com o tempo e com o esforço, cuja falta parece ter sido uma atribuição à carga de treinamento a que são submetidos: treinam muito pouco ou sequer treinam, não por falta de vontade, mas porque é deste modo que os fatos ocorrem em seu clube e nas equipes da categoria Junior. A crença parece ser de que precisam treinar mais e mais para serem mais competentes, mas que o clube não proporciona treinamento suficiente.

Por fim, a menor frequência de atribuições foi a características da tarefa, relacionadas à falta de estrutura do time, a dificuldades, geralmente financeiras, que o clube enfrenta e que leva à impossibilidade de investir em aspectos que dariam um maior nível de competência ao atleta, como por exemplo, bons equipamentos, locais adequados para treino e equipe de profissionais qualificados. Em outras palavras, o jogador acredita que não é bom porque a equipe em que joga não lhe dá condições de se desenvolver.

Quando analisadas em conjunto, os resultados mostraram que as causas utilizadas pelos jogadores para explicar seu maior nível de competência foram percebidas como mais internas e mais estáveis quando comparadas àquelas de atletas com menor percepção de competência, não havendo diferença para o controle pessoal. Assim, os jogadores dessa amostra fizeram atribuições a causas internas, estáveis e controláveis para explicar o maior nível de competência percebido e atribuições mais externas, mais instáveis e também passíveis de controle pessoal aos níveis mais baixos de competência percebida. Ambos os tipos de atribuição podem ser considerados otimistas, já que no primeiro caso permitem que sentimentos positivos, boas expectativas e disposições para ação sejam mantidos elevados e no segundo não deixam que sentimentos negativos, baixas expectativas e pouca disposição para ação sejam instalados. Resultados semelhantes foram encontrados, por exemplo, por Sousa, Rosado e Cabrita (2008), que buscaram descobrir as dimensões das causas atribuídas por 125 jogadores de futebol portugueses aos jogos em que avaliaram ter tido sua melhor e sua pior atuação na carreira. Os resultados indicaram que as causas atribuídas ao melhor desempenho já conseguido foram mais internas, estáveis e pessoalmente controláveis que aquelas atribuídas à pior atuação.

Em relação à diferença no locus da causalidade, os resultados parecem indicar a presença do egotismo atribuicional, uma tendência à proteção dos sentimentos através da admis- são de que apenas o que é bom está relacionado ao indivíduo e o que não é está ligado a causas mais externas.

Quanto ao grau de estabilidade da causa, a diferença encontrada parece também estar de acordo com o que escreveu Weiner (1985), que o fato de acreditar que resultados positivos são estáveis seria uma forma de manter as expectativas elevadas, enquanto acreditar que resultados negativos são instáveis implicaria na possibilidade de sua mudança.

$\mathrm{O}$ fato de não ter havido diferença em relação ao controle pessoal pode ser explicado pela observação de que, neste estudo, as causas eram atribuídas ao nível de competência global no futebol (algo que o indivíduo carrega o tempo todo) e não a algum resultado específico em tarefa de realização que acabara de ocorrer. De acordo com Santamaria e Furst (1994) a maioria das pesquisas em atribuição no esporte utiliza tarefas de realização, nas quais os indivíduos avaliam se obtiveram sucesso ou insucesso após o cumprimento imediato de uma tarefa específica.

Desta forma, acabaria sendo pouco funcional admitir que a causa de um resultado negativo em uma tarefa que acabou de acontecer é pessoalmente controlável, uma vez que isso poderia diminuir imediatamente a intensidade de sentimentos positivos, expectativas e, por consequência, a motivação. Já afirmar que esta causa foi incontrolável pode ser mais funcional e evitar que bons sentimentos, expectativas e motivação imediata diminuam. Por outro lado, admitir que a causa do menor nível de competência percebido está sob controle pessoal parece ser mais funcional que acreditar que ela é incontrolável, pois para o jogador é melhor pensar que, se ele quiser, pode fazer algo para mudar a situação e buscar maior nível de competência no futuro, ao invés de crer que ele não pode fazer nada para ser um melhor jogador. Neste caso, atribuir causas controláveis a situações avaliadas como negativas pode ser extremamente funcional, pois haverá expectativas de que as causas não são imutáveis e podem ser controladas e alteradas, mantendo a motivação em longo prazo.

Orbach, Singer e Murphey (1997), ao estudar as atribuições de causalidade em 60 jogadores de basquete, descobriram que atribuições controláveis ao insucesso em uma tarefa relacionada ao esporte fizeram com que o desempenho futuro dos atletas na mesma tarefa melhorasse. Rascle, Le Foll e Higgins (2008) e Le Foll, Rascle e Higgins (2008), trabalhando respectivamente com 41 e 31 golfistas iniciantes, encontraram que atribuições controláveis depois de tacadas mal sucedidas fizeram com que os jogadores gastassem mais tempo treinando e tivessem melhores expectativas.

Outro importante resultado encontrado, em que as análises de regressão indicaram que o nível de competência percebido é preditor significativo de $4 \%$ a $11 \%$ das três dimensões atribuicionais, sugere que o nível de competência percebido está mesmo ligado às atribuições feitas pelos atletas. Resultados semelhantes foram encontrados por Weiss, McAuley, Ebbeck \& Wiese (1990) que, ao estudarem as atribuições de causalidade feitas por 131 crianças praticantes de diversas modalidades esportivas, descobriram que as três dimensões causais tiveram $8,29 \%$ e $16,4 \%$ de sua variância explicada pelo nível de sucesso percebido em conjunto respectivamente com medidas de auto-estima física e social. 
Assim, a partir dessa constatação e baseado no modelo atribuicional da motivação intrapessoal de Weiner (2000) que prevê que as reações emocionais, expectativas e disposições para agir do indivíduo são influenciadas menos pela causa explicativa em si e mais por suas dimensões - ganha força a ideia de que a combinação do locus da causalidade, do grau de estabilidade e da controlabilidade pessoal da causa forma tipos distintos de explicação que influenciarão de diferentes formas os sentimentos do indivíduo, o que ele espera da situação no futuro e o quanto se dispõe a agir de uma determinada maneira, buscando ser um melhor jogador.

Nesta amostra, os resultados indicaram que, independente do tipo de atribuição efetuada ao nível de competência percebido, sentimentos positivos tiveram média mais elevada que os negativos. Ainda assim, aqueles com maior nível de competência percebido pareceram experimentar significativamente mais sentimentos positivos que aqueles com percepção de menor nível de competência. Por outro lado, não houve diferença entre os grupos em relação aos sentimentos negativos, o que permite supor que os jogadores tenham utilizado um tipo de atribuição otimista ao explicar a menor percepção de competência com causas externas, instáveis e controláveis. Tal atribuição pode ter contribuído para a proteção de seus sentimentos e impedido o surgimento de alto nível de emoções negativas.

Em relação às expectativas, aqueles sujeitos que fizeram atribuições internas, estáveis e controláveis à maior competência percebida apresentaram, de forma geral, médias mais elevadas do que aqueles que fizeram atribuições externas, instáveis e controláveis à menor percepção de competência. Tal resultado seria o esperado, afinal ter maior nível de competência deveria implicar em maiores expectativas. O interessante, porém, é que não houve entre os grupos diferença significativa do ponto de vista estatístico, ou seja, novamente uma atribuição otimista parece ter entrado em ação, conseguindo manter suficientemente elevadas as expectativas dos jogadores que acreditam não ter um nível tão elevado de competência.

Quanto às disposições para a ação foi possível observar que, de forma geral, aqueles que fizeram atribuições internas, estáveis e controláveis ao maior nível de competência percebido tiveram médias mais elevadas que aqueles que fizeram atribuições externas, instáveis e controláveis ao menor nível. Contudo, a diferença também não foi significativa, ou seja, os jogadores de futebol dessa amostra apresentaram disposições para agir semelhantes, o que mais uma vez sugere a presença de uma atribuição otimista, que protege suficientemente as disposições para agir dos atletas com menor percepção de competência.

Outro importante resultado que merece destaque é em relação à quais dimensões específicas são mais responsáveis por influenciar os sentimentos e expectativas. Foi encontrado no estudo aqui descrito que o controle pessoal é a dimensão mais influente, tanto nas emoções quanto nas expectativas dos jogadores dessa amostra, o que contraria o postulado geral de Weiner (1985) de que o locus da causalidade seria a dimensão mais ligada às emoções e o grau de estabilidade a mais ligada às expectativas dos indivíduos. Contudo, como o próprio Weiner (1985) admitiu, tais ligações não são rígidas, podendo haver mesmo diferentes percepções.
McAuley, Russell e Gross (1983) já haviam encontrado, estudando a atribuição de causalidade em mesa-tenistas, que, ao invés do locus da causalidade, o grau de controlabilidade pessoal era a dimensão mais importante para as emoções dos atletas. Os resultados de seu estudo mostraram que a combinação das dimensões da causa conseguiu predizer de 16 a $25 \%$ dos sentimentos positivos e de 3,2 a $16,3 \%$ dos sentimentos negativos, sendo que a controlabilidade da causa foi dimensão mais importante, ao explicar de 7,6 a 18,8\% da variância dos sentimentos de satisfação, orgulho, confiança, gratidão e surpresa, enquanto a estabilidade explicou até $10 \%$ e o locus no máximo $5 \%$ dessas emoções.

De acordo com os autores, a discrepância em relação ao locus da causalidade seria uma característica do ambiente esportivo, uma vez que a maioria dos estudos de Bernard Weiner foi feito em contexto acadêmico. A hipótese seria que, no esporte, o nível de controle sobre o desempenho é mais valorizado por outras pessoas, que ofereceriam recompensas e punições ao atleta de acordo com a percepção deste nível e não simplesmente conforme a percepção de que o atleta tem ou não relação com a causa do desempenho. Rees, Ingledew e Hardy (2005), ao analisarem a produção acadêmica sobre o processo atribuicional no esporte, corroboram esta hipótese e afirmam que em contexto esportivo o controle pessoal é realmente uma dimensão mais significativa que o locus da causalidade.

Se em relação às dimensões que influenciariam os sentimentos e expectativas dos indivíduos, houve certa discrepância justificada em relação à teoria proposta por Weiner (1985, 2000), nos resultados relativos às disposições para a ação ficou claro que a interação entre sentimentos e expectativas, conforme sugere o mesmo autor, explica mesmo grande parte da disposição do atleta para agir. Tal constatação pode ser a chave para entender parte da motivação intrapessoal de um atleta, no caso desta amostra, de jogadores de futebol.

Desta forma, conforme indicam os resultados deste estudo, um comportamento mais ou menos motivado de um atleta pode ser resultado da interação entre os sentimentos (principalmente os negativos) e as expectativas que ele experiencia em relação a alguma tarefa em determinado momento.

Desta forma, sabendo-se que as causas utilizadas para explicar o nível de competência percebido parecem mesmo influenciar os sentimentos, expectativas e disposições para agir dos atletas, fica a sugestão aos treinadores ou a qualquer pessoa que possa fornecer feedback atribuicional direto aos atletas sobre seu nível de competência, para que o façam utilizando causas internas, estáveis e controláveis diante de alta percepção de competência pessoal e causas externas, instáveis e controláveis quando o atleta estiver com a percepção de que não é um jogador tão bom. E principalmente, que indiquem que a causa responsável pelo maior ou menor nível de competência pode ser pessoalmente controlada. Se os resultados descritos na teoria da atribuição de causas, e aqui corroborados, estiverem certos, jogadores de futebol terão sentimentos e expectativas positivos que poderão levá-los a ter mais motivação e um melhor desempenho durante a prática esportiva.

Aos demais pesquisadores fica o pedido para que este estudo seja replicado e que os resultados sejam comparados. Também que o tema seja investigado em outras amostras, em 
esportes individuais e coletivos, em participantes femininos e que sejam buscadas formas de medir a influência dos tipos de atribuição no comportamento do atleta durante a atividade esportiva e não somente nas suas disposições para o comportamento. A construção de instrumentos validados e fidedignos pode ser um caminho útil a ser seguido no cumprimento de tal objetivo, bem como o teste de situações de (re) treinamento das atribuições (em que são dadas instruções atribuicionais otimistas diante de sucessos e principalmente de insucessos). Espera-se, por fim, que isto seja feito não apenas com atletas de alto rendimento, mas também com aqueles envolvidos na prática rotineira e não profissional do esporte.

\section{Referências}

Bardin, L. (1970). Análise de conteúdo. Lisboa: Edições 70.

Dela Coleta, J. A., \& Godoy, S. A. (1986). Atribuição de causalidade ao sucesso e fracasso e reações emocionais: pesquisas brasileiras com os modelos de Bernard Weiner. Psicologia: Teoria e Pesquisa, 2(2), 145-156.

Heider, F. (1958). The psychology of interpersonal relations. New York: John Wiley.

Le Foll, D., Rascle, O., \& Higgins, N. C. (2006). Persistence in a putting task during perceived failure: influence of stateattributions and attributional style. Applied Psychology: An International Review, 55(4), 586-605.

Le Foll, D., Rascle, O., \& Higgins, N. C. (2008). Attributional feedback-induced changes in functional and dysfunctional attributions, expectations of success, hopefulness, and shortterm persistence in a novel sport. Psychology of Sport and Exercise, 9, 77-101.

McAuley, E., Russell, D., \& Gross, J. B. (1983). Affective consequences of winning and losing: an attributional analysis. Journal of Sport Psychology, 5, 278-287.

Orbach, I., Singer, R. N., \& Murphey, M. (1997). Changing attributions with an attributional training technique related to basketball dribbling. The Sport Psychologist, 11, 294-304.

Rascle, O., Le Foll, D., \& Higgins, N. C. (2008). Attributional retraining alters novice golfers' free practice behavior. Journal of Applied Sport Psychology, 20(2), 157-164.

Rees, T., Ingledew, D. K., \& Hardy, L. (2005). Attribution in sport psychology: Seeking congruence between theory, research and practice. Psychology of Sport and Exercise, 6, 189-204.
Rodrigues, A. (2007). Psicologia social para iniciantes. Petropolis: Vozes.

Rudisill, M. E. (1989). Influence of perceived competence and causal dimension orientation on expectations, persistence, and performance during perceived failure. Research Quarterly, 60(2), 166-175.

Santamaria, V. L., \& Furst, D. M. (1994). Distance runner's causal attributtions for most successful and least successful races. Journal of Sport Behavior, 17(1), 43-49.

Sousa, P. M., Rosado, A. B., \& Cabrita, T. M. (2008). Análise das atribuições causais do sucesso e do insucesso na competição, em função do nível competitivo dos futebolistas portugueses. Psicologia: Reflexão e Crítica, 21(2), 203-211.

Weiner, B. (1979). A theory of motivation for some classroom experiences. Journal of Education Psychology, 71, 3-25.

Weiner, B. (1985). Attributional theory of achievement motivation and emotion. Psychological Review, 92, 548-573.

Weiner, B. (2000). Intrapersonal and interpersonal theories of motivation from an attributional perspective, Educational Psychology Review, 12, 1-14.

Weiner, B., Frieze, I., Kukla, A., Reed, L., Rest, S., \& Rosenbaum, R. M. (1972). Perceiving the causes of success and failure. Em Jones, D. E. Kanouse, H. H. Kelley, R. E. Nisbett, J. Valins \& B. Weiner (Eds.), Attribution: Perceiving the causes of behavior (95-120). Morristown: General Learning.

Weiner, B., Russell, D., \& Lerman, D. (1978). Affective consequences of causal ascription. Em J. H. Harvey, W. J. Ickes $\&$ R. F. Kidd (Eds.), New directions in attribution research, (Vol.2, pp.59-90), New York: Lawrence Erlbaum.

Weiss, M. R., McAuley, E., Ebbeck, V., \& Wiese, D. M. (1990). Self-esteem and causal attributions for children's physical and social competence in sport. Journal of Sport and Exercise Psychology, 12, 21-36. 